\title{
Intracranial Hemorrhage in a Patient with TAFRO Syndrome Treated with Cyclosporine A and Rituximab
}

\author{
Yuina Akagi ${ }^{1,2}$, Takashi Kato ${ }^{1}$, Yusuke Yamashita ${ }^{1,2}$, Hiroki Hosoi ${ }^{1}$, Shogo Murata ${ }^{1}$, Shuto Yamamoto ${ }^{3}$, \\ Kenji Warigaya ${ }^{4}$, Taisei Nakao ${ }^{2}$, Shinichi Murata ${ }^{4}$, Takashi Sonoki ${ }^{1}$ and Shinobu Tamura ${ }^{1, *}$ (D) \\ 1 Department of Hematology/Oncology, Wakayama Medical University, Wakayama 6418509, Japan; \\ kurenainoyuni@yahoo.co.jp (Y.A.); ktakashi@wakayama-med.ac.jp (T.K.); \\ yyyamash@wakayama-med.ac.jp (Y.Y.); hiro-hosoi@hotmail.co.jp (H.H.); shogo@wakayama-med.ac.jp (S.M.); \\ sonoki@wakayama-med.ac.jp (T.S.) \\ 2 Department of Internal Medicine, Naga Municipal Hospital, Wakayama 6496414, Japan; t.nakao@nagahp.jp \\ 3 Department of Nephrology, Wakayama Medical University, Wakayama 6418509, Japan; \\ shu-yama@wakayama-med.ac.jp \\ 4 Department of Diagnostic Pathology, Wakayama Medical University, Wakayama 6418509, Japan; \\ ketunai@wakayama-med.ac.jp (K.W.); smurata@wakayama-med.ac.jp (S.M.) \\ * Correspondence: stamura@wakayama-med.ac.jp; Tel.: +81-73-441-0665; Fax: +81-73-441-0653
}

check for updates

Citation: Akagi, Y.; Kato, T.; Yamashita, Y.; Hosoi, H.; Murata, S.; Yamamoto, S.; Warigaya, K.; Nakao, T.; Murata, S.; Sonoki, T.; et al. Intracranial Hemorrhage in a Patient with TAFRO Syndrome Treated with Cyclosporine A and Rituximab. Medicina 2021, 57, 971. https:/ / doi.org/10.3390/medicina57090971

Academic Editor: Michal Nowicki

Received: 29 July 2021

Accepted: 15 September 2021

Published: 16 September 2021

Publisher's Note: MDPI stays neutral with regard to jurisdictional claims in published maps and institutional affiliations.

Copyright: (c) 2021 by the authors. Licensee MDPI, Basel, Switzerland. This article is an open access article distributed under the terms and conditions of the Creative Commons Attribution (CC BY) license (https:// creativecommons.org/licenses/by/ $4.0 /)$.

\begin{abstract}
TAFRO syndrome, a rare subtype of idiopathic multicentric Castleman disease, manifests as thrombocytopenia, anasarca, fever, reticulin fibrosis, and organomegaly. Thrombotic microangiopathy, including renal dysfunction, is frequently associated with this syndrome. TAFRO syndrome can be life threatening and show rapid progression, and the diagnosis and management of this disorder remain challenging. A 48-year-old woman was diagnosed with TAFRO syndrome complicated by thrombotic microangiopathy based on the clinical and histopathological findings. After receiving high-dose steroids, her thrombocytopenia and anasarca did not improve. The patient subsequently received a combination of cyclosporine A and rituximab as second-line therapy, which resulted in a significant gradual improvement in the clinical symptoms. Meanwhile, her platelet count increased to more than $40 \times 10^{9} / \mathrm{L}$; however, she developed intracranial hemorrhage. Following surgical evacuation, the patient recovered with an achievement of sustained remission. Based on these findings, attention should be paid to life-threatening bleeding associated with local thrombotic microangiopathy even when intensive treatment is administered for TAFRO syndrome.
\end{abstract}

Keywords: TAFRO syndrome; thrombotic microangiopathy; cyclosporine A; rituximab; intracranial hemorrhage

\section{Introduction}

TAFRO syndrome is a rare systemic inflammatory disorder characterized by thrombocytopenia, anasarca, reticulin fibrosis of the bone marrow, renal dysfunction, and organomegaly [1,2]. In 2010, three patients with TAFRO syndrome were first described in Japan [3]. Histopathological evaluation of the lymph nodes from patients with TAFRO syndrome revealed characteristics that were similar to those in patients with idiopathic multicentric Castleman's disease, particularly the hyaline-vascular variant $[1,2]$. Nonetheless, TAFRO syndrome clinically differs from typical idiopathic multicentric Castleman's disease, considering that the former is usually a rapid, aggressive, and life-threatening condition. However, TAFRO syndrome was later classified as a variant of idiopathic multicentric Castleman's disease based on the histopathological similarities [4]. Notably, studies have found that corticosteroids have limited efficacy against TAFRO syndrome, which generally requires additional immunosuppressants, including cyclosporine A, tacrolimus, and cyclophosphamide [2,5-7]. Considering that the pathogenesis and symptomatology of TAFRO syndrome have been associated with the excessive release of interleukin-6 (IL-6) 
and vascular endothelial growth factor (VEGF) [1,2], tocilizumab, a humanized anti-IL-6 receptor antibody, has emerged as a therapeutic option for patients with TAFRO syndrome. Moreover, rituximab, an anti-CD20 antibody, has also been successfully used in combination with corticosteroids and/or immunosuppressants [3,8-10]. In 2016, Masaki et al. proposed diagnostic criteria, severity classification, and treatment strategy for TAFRO syndrome [2]. Since then, case reports of TAFRO syndrome have gradually increased worldwide, although its etiology remains unclear.

Herein, we present a case of TAFRO syndrome diagnosed using bone marrow and kidney histopathology that suddenly developed intracranial hemorrhage during combination therapy with cyclosporine A and rituximab.

\section{Case Report}

A 48-year-old woman was admitted because of persistent fever and abdominal distention for 2 weeks. There was no notable previous medical or familiar history, and the patient had never smoked or consumed alcohol. Within a week after admission, she developed pleural effusion, ascites, hepatosplenomegaly, renal dysfunction, and thrombocytopenia of unknown etiology. Despite antibiotic and diuretic administration, her general condition rapidly worsened. Given the suspicion of a hematological disorder, the patient was transferred to our hospital for further examination.

Upon transfer to our hospital, she was found to have a fever of $37.3{ }^{\circ} \mathrm{C}$, heart rate of 90 beats / $\mathrm{min}$, blood pressure of $144 / 83 \mathrm{mmHg}$, and oxygen saturation of $97 \%$ on room air. Physical examination revealed diffusely decreased respiratory sounds in the right lung, severe abdominal distension, and pitting edema of the lower extremities. No peripheral lymph nodes were palpable, while laboratory studies revealed mild thrombocytopenia (platelet count of $123 \times 10^{9} / \mathrm{L}$ ) and elevated levels of alkaline phosphatase (325 IU/L), soluble interleukin-2 receptor $(981 \mathrm{U} / \mathrm{mL})$, C-reactive protein (CRP) $(3.0 \mathrm{mg} / \mathrm{dL})$, and creatinine $(1.71 \mathrm{mg} / \mathrm{dL})$, along with proteinuria and microscopic hematuria (Table 1). Although the patient was positive for anti-Sjögren's-syndrome-related antigen A and antihistidyl-tRNA synthetase antibodies, she did not fulfill the criteria for connective tissue disease. Screening tests for hepatitis $B$ virus, hepatitis $C$ virus, cytomegalovirus, and human immunodeficiency virus were negative. Although her serum IL-6 level was almost normal $(5.0 \mathrm{pg} / \mathrm{mL}$; reference range $<4.0 \mathrm{pg} / \mathrm{mL})$, elevated serum VEGF levels were noted $(256 \mathrm{pg} / \mathrm{mL}$; reference range $<38.3 \mathrm{pg} / \mathrm{mL})$. Computed tomography $(\mathrm{CT})$ revealed right pleural effusion, massive ascites, and hepatosplenomegaly without enlarged lymph nodes (Figure 1), and bone marrow biopsy showed hypercellular marrow with megakaryocyte hyperplasia (Figure 2, arrowheads) and mild reticulin fibrosis (Figure 2, arrow).

Table 1. Laboratory data of our patient with TAFRO syndrome at the transfer to our hospital.

\begin{tabular}{|c|c|c|c|c|c|c|c|c|}
\hline \multicolumn{3}{|c|}{ Complete Blood Count } & \multicolumn{3}{|c|}{ Chemistry } & \multirow{2}{*}{$\begin{array}{c}\text { Calcium } \\
\text { Total Bilirubin }\end{array}$} & \multirow{2}{*}{$\begin{array}{l}9.4 \\
0.5\end{array}$} & \multirow{2}{*}{$\begin{array}{l}\mathbf{m g} / \mathbf{d L} \\
\mathrm{mg} / \mathrm{dL}\end{array}$} \\
\hline $\begin{array}{c}\text { White } \\
\text { Blood Cells }\end{array}$ & 11.1 & $\times 10^{9} / \mathrm{L}$ & Total Protein & 5.9 & $\mathrm{~g} / \mathrm{dL}$ & & & \\
\hline Neutrophil & 78 & $\%$ & Albumin & 3.0 & $\mathrm{~g} / \mathrm{dL}$ & $\begin{array}{l}\text { C-Reactive } \\
\text { Protein }\end{array}$ & 3.0 & $\mathrm{mg} / \mathrm{dL}$ \\
\hline Eosinophil & 0 & $\%$ & Creatine Kinase & 87 & $\mathrm{IU} / \mathrm{L}$ & $\operatorname{IgG}$ & 1008 & $\mathrm{mg} / \mathrm{dL}$ \\
\hline Basophil & 0 & $\%$ & $\begin{array}{c}\text { Aspartate } \\
\text { Transaminase }\end{array}$ & 16 & $\mathrm{IU} / \mathrm{L}$ & $\operatorname{Ig} \mathrm{A}$ & 60 & $\mathrm{mg} / \mathrm{dL}$ \\
\hline Monocyte & 7 & $\%$ & $\begin{array}{c}\text { Alanine } \\
\text { Transaminase }\end{array}$ & 7 & $\mathrm{IU} / \mathrm{L}$ & $\operatorname{IgM}$ & 112 & $\mathrm{mg} / \mathrm{dL}$ \\
\hline Lymphocyte & 12 & $\%$ & $\begin{array}{c}\text { Lactate } \\
\text { Dehydrogenase }\end{array}$ & 187 & $\mathrm{IU} / \mathrm{L}$ & $\operatorname{IgG} 4$ & 11 & $\mathrm{mg} / \mathrm{dL}$ \\
\hline Myelocytes & 1 & $\%$ & $\begin{array}{c}\text { Alkaline } \\
\text { Phosphatase }\end{array}$ & 325 & $\mathrm{IU} / \mathrm{L}$ & TSH & 2.38 & $\mu \mathrm{IU} / \mathrm{mL}$ \\
\hline
\end{tabular}


Table 1. Cont.

\begin{tabular}{|c|c|c|c|c|c|c|c|c|}
\hline \multicolumn{3}{|c|}{ Complete Blood Count } & \multicolumn{3}{|c|}{ Chemistry } & \multirow{2}{*}{$\begin{array}{l}\text { Calcium } \\
\text { Free T4 }\end{array}$} & \multirow{2}{*}{$\begin{array}{l}9.4 \\
1.39\end{array}$} & \multirow{2}{*}{$\begin{array}{l}\mathrm{mg} / \mathrm{dL} \\
\mathrm{ng} / \mathrm{mL}\end{array}$} \\
\hline Metamyelocytes & 2 & $\%$ & $\begin{array}{c}\gamma \text {-Glutamyl } \\
\text { Transpeptidase }\end{array}$ & 32 & $\mathrm{IU} / \mathrm{L}$ & & & \\
\hline $\begin{array}{l}\text { Red Blood } \\
\text { Cells }\end{array}$ & 4.14 & $\times 10^{12} / \mathrm{L}$ & Cholinesterase & 285 & $\mathrm{IU} / \mathrm{L}$ & Soluble IL-2R & 981 & $\mathrm{U} / \mathrm{mL}$ \\
\hline Hemoglobin & 10.7 & $\mathrm{~g} / \mathrm{dL}$ & Amylase & 63 & IU/L & Ferritin & 118 & $\mathrm{ng} / \mathrm{mL}$ \\
\hline Reticulocytes & 77 & $\times 10^{9} / \mathrm{L}$ & Creatinine & 1.71 & $\mathrm{mg} / \mathrm{dL}$ & & & \\
\hline \multirow[t]{2}{*}{ Platelets } & 123 & $\times 10^{9} / \mathrm{L}$ & Uric Acid & 8.4 & $\mathrm{mg} / \mathrm{dL}$ & \multicolumn{3}{|c|}{ Coagulation system } \\
\hline & & & Blood Urea Nitrogen & 32.7 & $\mathrm{mg} / \mathrm{dL}$ & APTT & 32.3 & $\mathrm{~s}$ \\
\hline \multicolumn{3}{|c|}{ Serum Cytokine } & Sodium & 139 & $\mathrm{mEq} / \mathrm{L}$ & $\begin{array}{l}\text { Prothrombin } \\
\text { time }\end{array}$ & 1.04 & $\mathrm{~s}$ \\
\hline IL-6 * & 5.0 & $\mathrm{pg} / \mathrm{mL}$ & Potassium & 4.3 & $\mathrm{mEq} / \mathrm{L}$ & Fibrinogen & 423 & $\mathrm{mg} / \mathrm{dL}$ \\
\hline VEGF * & 256 & $\mathrm{pg} / \mathrm{mL}$ & Chloride & 104 & $\mathrm{mEq} / \mathrm{L}$ & D-dimer & 8.1 & $\mu \mathrm{g} / \mathrm{mL}$ \\
\hline
\end{tabular}

APTT, activated partial thromboplastin time; Ig, immunoglobulin; IL-2R, interleukin-2 receptor; IL-6, interleukin-6; TSH, thyroid-stimulating hormone, VEGF: vascular endothelial growth factor. * The reference ranges of IL- 6 and VEGF were $<4.0 \mathrm{pg} / \mathrm{mL}$ and $<38.3 \mathrm{pg} / \mathrm{mL}$, respectively.

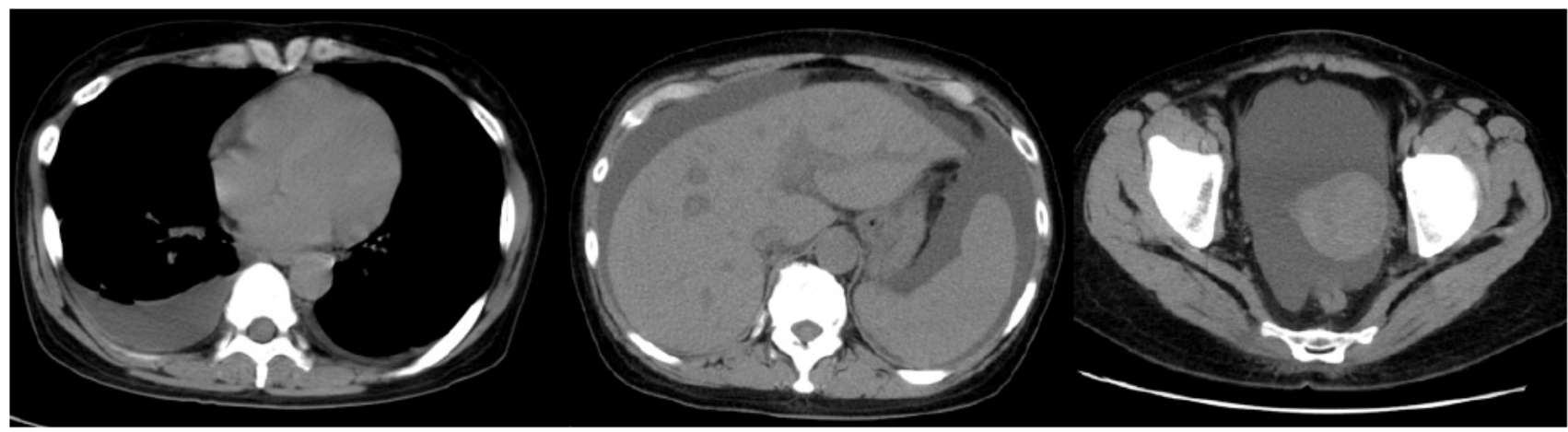

Figure 1. Chest and abdominal computed tomography (CT) images of the patient on transfer to our hospital. CT images show right-sided pleural effusion, ascites, and hepato-splenomegaly.

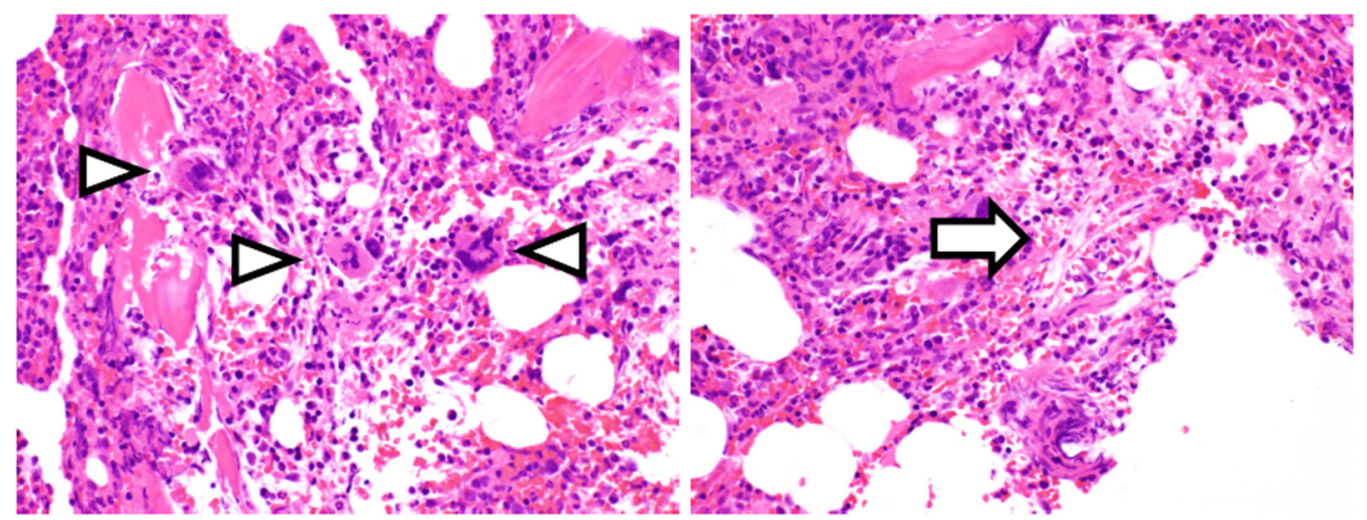

Figure 2. Bone marrow lesions in our patient. Hematoxylin and eosin staining shows a hypercellular marrow with megakaryocyte clusters (arrowheads) and mild reticulin fibrosis (arrow) $(\times 200)$.

On the third day of admission, renal biopsy was performed to evaluate acute kidney injury regardless of the decrease in platelet count $\left(79 \times 10^{9} / \mathrm{L}\right)$. The aforementioned clinical findings fulfilled all three major and three minor criteria for TAFRO syndrome according to the Japanese diagnostic criteria published in 2015 [2]. On the fifth day of admission, a diagnosis of TAFRO syndrome was established based on the clinical, laboratory, and histopathological findings. Additionally, the patient was considered to have moderately severe disease (score of five out of 12 points) [2]. Moreover, the final report detailing the pathological findings of the renal biopsy revealed prominent swelling and increased number of glomerular endothelial cells with glomerular endothelial injury due to renal 
thrombotic microangiopathy (Figure 3). These renal biopsy findings were also consistent with those of TAFRO syndrome.
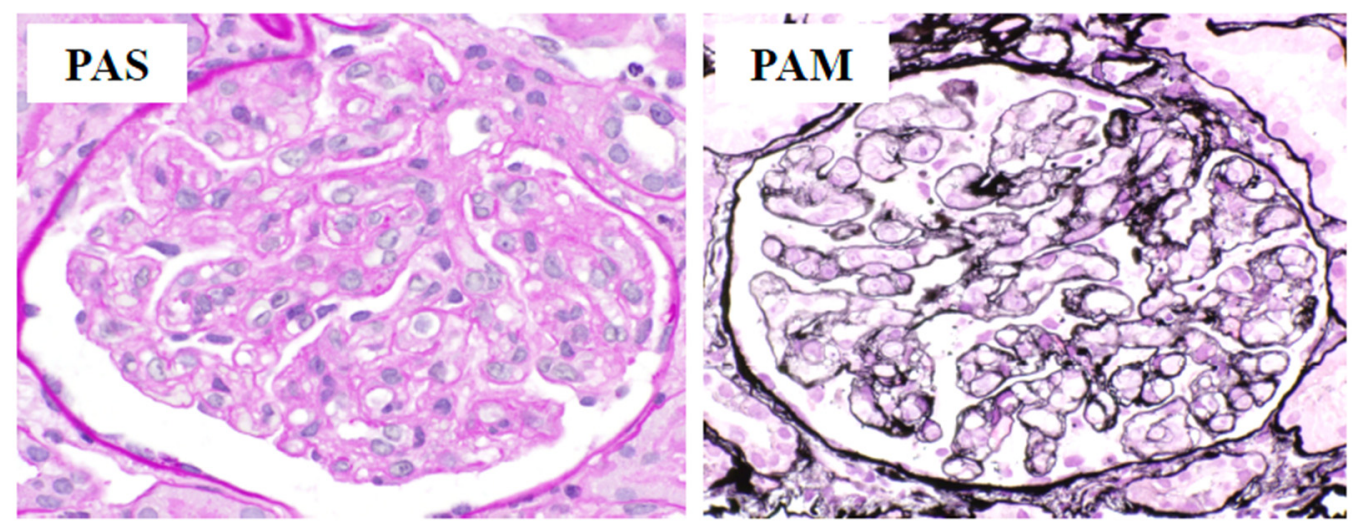

Figure 3. Kidney lesions in our patient. Periodic acid-Schiff and periodic acid methenamine silver staining shows prominent swelling and increased glomerular endothelial cells $(\times 400)$.

The clinical course after admission to our hospital is shown in Figure 4. Soon after the diagnosis of TAFRO syndrome, the patient was initially treated with $60 \mathrm{mg}(1 \mathrm{mg} / \mathrm{kg}$ of body weight) of oral prednisolone (PSL) daily; however, an adequate response was not achieved. Therefore, methylprednisolone pulse therapy $(1000 \mathrm{mg} /$ day $)$ was administered for three consecutive days followed by PSL $60 \mathrm{mg}$ ( $1 \mathrm{mg} / \mathrm{kg}$ of body weight) per day. Considering that her symptoms and clinical course did not respond to steroid therapy, platelet transfusion and ascites paracentesis were performed. Additionally, she often experienced a sudden and transient drop in blood pressure, pulse, and oxygen saturation. On the 11th day of admission, continuous hemodiafiltration was required because of oliguric renal failure. Subsequently, oral cyclosporine A (CyA, $4 \mathrm{mg} / \mathrm{kg} /$ day in two divided doses) and weekly rituximab ( $375 \mathrm{mg} / \mathrm{m}^{2}$, four infusions) were selected as the second-line treatment, along with steroid tapering (Figure 4). Although the patient's serum IL-6 level was found to be within the normal range immediately before the first infusion of rituximab, her serum VEGF level was still high at $92 \mathrm{pg} / \mathrm{mL}$ (reference range $<38.3 \mathrm{pg} / \mathrm{mL}$ ). After initiating second-line treatment, renal dysfunction, thrombocytopenia, and CRP levels gradually improved, and hemodialysis was terminated on the 38th day of admission (Figure 4). The patient displayed a stable circulatory status, with a gradual decrease in anasarca and ascites.

On the 39th day of admission, the patient developed severe headache and vomiting. A cranial CT scan revealed cerebral and subarachnoid hemorrhage (Figure 4), despite having a platelet count of $42 \times 10^{9} / \mathrm{L}$ with normal coagulation parameters. The patient subsequently underwent an emergency craniotomy for evacuation. Postoperative angiography revealed no cerebral aneurysm or brain arteriovenous malformation. Although prolonged rehabilitation was required after the surgery, the patient exhibited no residual neurological sequelae. On the 84th day of admission, the patient was discharged ambulatory and maintained remission and normal renal function with oral CyA $(150 \mathrm{mg} /$ day, $3 \mathrm{mg} / \mathrm{kg} /$ day in two divided doses) monotherapy for more than a year. 


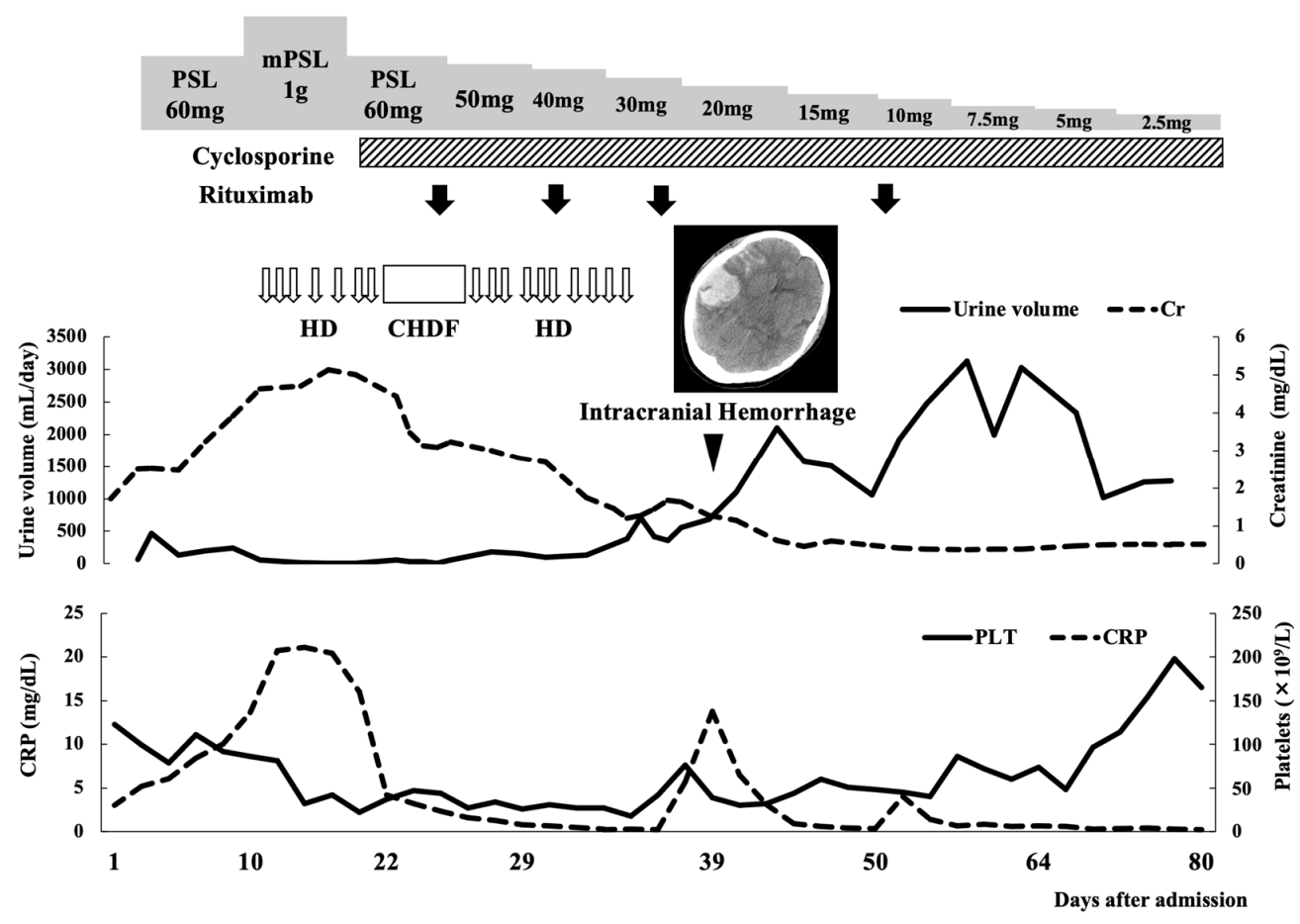

Figure 4. Clinical course of the patient after transfer to our hospital. Cranial computed tomography imaging of the patient shows a life-threating hemorrhage in the right subarachnoid space and cerebral hemisphere. CHDF, continuous hemodiafiltration; $\mathrm{Cr}$, creatinine; CRP, C-reactive protein; HD, hemodialysis; PLT, platelets; PSL, prednisolone.

\section{Discussion}

An increasing number of case reports with TAFRO syndrome has recently described renal percutaneous biopsy among the diagnostic procedures, despite low platelet counts. Given that our patient had a platelet count exceeding $7 \times 10^{9} / \mathrm{L}$, renal biopsy was performed without any complications. The main pathological findings of renal involvement in TAFRO syndrome are thrombotic microangiopathy-like glomerulopathy and membranoproliferative glomerulonephritis-like lesions [11,12]. In particular, thrombotic microangiopathy-like glomerulopathy is considered a typical pathological characteristic of acute-phase TAFRO syndrome [11,12]. According to the pathologist, the renal histology in our patient was consistent with thrombotic microangiopathy-like findings, suggesting that our patient was in the acute phase of TAFRO syndrome. Moreover, high levels of serum VEGF have been observed in most patients with TAFRO syndrome [1,2]. The highly elevated serum VEGF levels in our patient upon diagnosis could have aggravated endothelial glomerular injury, which was followed by local thrombotic microangiopathy.

Only one case of intracranial hemorrhage during the clinical course of TAFRO syndrome has been previously reported. This particular case involved an elderly patient with TAFRO syndrome who received steroids and tocilizumab and developed cerebral hemorrhage despite a platelet count of $80 \times 10^{9} / \mathrm{L}$, with the occurrence of death soon after due to aspiration pneumonia [13]. To our knowledge, this is the first report of a patient surviving TAFRO syndrome complicated by an intracranial hemorrhage, although several cases of intracranial hemorrhage during the course of idiopathic multicentric Castleman's disease have been published [14,15]. The risk of bleeding in TAFRO syndrome has been attributed to thrombocytopenia. However, although our patient had achieved a platelet count of $42 \times 10^{9} / \mathrm{L}$ when intracranial hemorrhage occurred, no cerebral aneurysm or arteriovenous malformation on cerebral angiography were observed. As such, the findings presented herein, as well as in a previously reported case [13], suggest little correlation between the platelet count and intracranial hemorrhage in patients with TAFRO syndrome. Moreover, we assumed that our patient developed endothelial brain injury due to local 
thrombotic microangiopathy, similar to that observed in the kidneys, which resulted in an intracranial hemorrhage. Therefore, although intensive immunosuppressive therapy is required for the clinical management of TAFRO syndrome, attention should also be paid to life-threatening bleeding.

Although the etiology of TAFRO syndrome, as well as the pathogenesis of idiopathic multicentric Castleman's disease, are yet to be elucidated, the excessive production of proinflammatory cytokines, such as IL-6, can cause some of the symptoms associated with these diseases [9]. In fact, patients with TAFRO syndrome have also been shown to exhibit elevated serum levels of both IL-6 and VEGF $[1,2,16]$. Tocilizumab, an anti-IL-6 receptor antibody, has been widely used as a second-line treatment option for corticosteroidresistant TAFRO syndrome [5,17-20]. Meanwhile, previous studies have also reported that patients with TAFRO syndrome who had normal serum IL-6 levels exhibited an inadequate response to tocilizumab $[5,10,18-20]$. In the present case, laboratory data before second-line treatment showed increased VEGF levels but normal IL-6 levels. Therefore, tocilizumab was not selected for our patient who was refractory to corticosteroid therapy. Some patients with tocilizumab resistance have been successfully treated with rituximab therapy [17-20], although the mechanism of action remains unclear. Recently, a retrospective study in Japan suggested that rituximab was a more effective second-line treatment than CyA or tocilizumab [20]. The clinical response to the additional rituximab in our patient also supports this notion, considering that the suppression of mature B cells by anti-CD20 antibodies improves clinical remission in patients with TAFRO syndrome.

Serum VEGF and circulating CD8 $+\mathrm{T}$ cells have been reported to be increased in non-Japanese patients with TAFRO syndrome [21-24]. Recent studies found that the mTOR (mammalian target of rapamycin) signaling pathway, which was critical to VEGF expression and CD8+ T cell activation, was elevated in such patients [22,23]. Furthermore, transcriptome analysis revealed that signature genes associated with interferon type I (IFN-I), which is one of the upstream regulators of mTOR signaling, were identified in CD8+ T cells, NK cells, and monocytes obtained from patients with TAFRO syndrome [24]. The overproduction of IFN-I in immune cells has been associated with the development of autoimmune diseases such as systemic lupus erythematous [25]. Notably, treatment with mTOR inhibitor has been shown to be effective in some patients with tocilizumabrefractory TAFRO syndrome [22]. These findings suggest that IFN-I-induced activation of mTOR signaling pathway serves a central role in the pathogenesis of TAFRO syndrome and develops autoimmune features such as thrombocytopenia.

\section{Conclusions}

Here, we have described our experience with a patient with TAFRO syndrome who was successfully treated with CyA and rituximab; however, she developed unexpected intracranial hemorrhage during the clinical course. Nonetheless, the efficacy of rituximab therapy for TAFRO syndrome requires further evaluation in prospective studies. Furthermore, clinicians should pay greater attention to life-threatening bleeding triggered by local thrombotic microangiopathy despite apparent improvements in the disease condition.

Author Contributions: Conceptualization, Y.A. and S.T.; methodology, T.K., Y.Y., H.H., S.M. (Shogo Murata), S.Y. and K.W.; data analysis, T.K., Y.Y., H.H., S.M. (Shinichi Murata), S.Y. and K.W.; writingoriginal draft preparation, Y.A. and S.T.; writing-review and editing, T.N., S.M. (Shinichi Murata) and T.S. All authors have read and agreed to the published version of the manuscript.

Funding: This research received no external funding.

Institutional Review Board Statement: This study was conducted in accordance with the tenets of the Declaration of Helsinki and was approved by the institutional review board of Wakayama Medical University (approval number: 57, approved on 31 July 2015).

Informed Consent Statement: Informed consent was obtained from the relatives of the patient.

Data Availability Statement: All data are included in the main text. 
Acknowledgments: This work was supported by JSPS KAKENHI (Grant Number 20K08718) from the Ministry of Education, Culture, Sports, Science, and Technology of Japan.

Conflicts of Interest: The authors declare no conflict of interest.

\section{References}

1. Kawabata, H.; Takai, K.; Kojima, M.; Nakamura, N.; Aoki, S.; Nakamura, S.; Kinoshita, T.; Masaki, Y. Castleman-Kojima disease (TAFRO syndrome): A novel systemic inflammatory disease characterized by a constellation of symptoms, namely, thrombocytopenia, ascites (anasarca), microcytic anemia, myelofibrosis, renal dysfunction, and organomegaly: A status report and summary of Fukushima (6 June 2012) and Nagoya meetings (22 September 2012). J. Clin. Exp. Hematop. 2013, 53, 57-61. [CrossRef] [PubMed]

2. Masaki, Y.; Kawabata, H.; Takai, K.; Kojima, M.; Tsukamoto, N.; Ishigaki, Y.; Kurose, N.; Ide, M.; Murakami, J.; Nara, K.; et al. Proposed diagnostic criteria, disease severity classification and treatment strategy for TAFRO Syndrome. Int. J. Hematol. 2016, 103, 686-692. [CrossRef] [PubMed]

3. Takai, K.; Nikkuni, K.; Shibuya, H.; Hashidate, H. Thrombocytopenia with mild bone marrow fibrosis accompanied by fever, pleural effusion, ascites and hepatosplenomegaly. Rinsho Ketsueki 2010, 51, 320-325.

4. Fajgenbaum, D.C.; van Rhee, F.; Nabel, C.S. HHV-8-negative, idiopathic multicentric Castleman disease: Novel insights into biology, pathogenesis, and therapy. Blood 2014, 123, 2924-2933. [CrossRef] [PubMed]

5. Yamaga, Y.; Tokuyama, K.; Kato, T.; Yamada, R.; Murayama, M.; Ikeda, T.; Yamakita, N.; Kunieda, T. Successful treatment with cyclosporin A in tocilizumab-resistant TAFRO syndrome. Intern. Med. 2016, 55, 185-190. [CrossRef]

6. Shirai, T.; Onishi, A.; Waki, D.; Saegusa, J.; Morinobu, A. Successful treatment with tacrolimus in TAFRO syndrome, two case reports and literature review. Medicine 2018, 97, e11045. [CrossRef]

7. Kikuchi, T.; Shimizu, T.; Toyama, T.; Abe, R.; Okamoto, S. Successful treatment of TAFRO syndrome with tocilizumab, prednisone, and cyclophosphamide. Intern. Med. 2017, 56, 2205-2211. [CrossRef]

8. José, F.F.; Kerbauy, L.N.; Perini, G.F.; Blumenschein, D.I.; Pasqualin, D.D.C.; Malheiros, D.M.A.C.; Campos Neto, G.C.; de Souza Santos, F.P.; Piovesan, R.; Hamerschlak, N. A life-threatening case of TAFRO syndrome with dramatic response to tocilizumab, rituximab, and pulse steroids: The first case report in Latin America. Medicine 2017, 96, e6271. [CrossRef]

9. Tsurumi, H.; Fujigaki, Y.; Yamamoto, T.; Iino, R.; Taniguchi, K.; Nagura, M.; Arai, S.; Tamura, Y.; Ota, T.; Shibata, S.; et al. Remission of refractory ascites and discontinuation of hemodialysis after additional rituximab to long-term glucocorticoid therapy in a patient with TAFRO syndrome. Intern. Med. 2018, 57, 1433-1438. [CrossRef]

10. Noda, Y.; Saka, Y.; Kato, A.; Mimura, T.; Naruse, T. Successful rituximab treatment of TAFRO syndrome with pathological findings of glomerular endothelial damage. Clin. Nephrol. Case Stud. 2018, 6, 16-20. [CrossRef]

11. Nagayama, Y.; Yamano, M.; Yagame, M.; Nariyama, T.; Takahashi, M.; Kawamoto, M.; Matsui, K. TAFRO syndrome as a cause of glomerular microangiopathy: A case report and literature review. BMC Nephrol. 2019, 20, 375. [CrossRef] [PubMed]

12. Zhou, Q.; Zhang, Y.; Zhou, G.; Zhu, J. Kidney biopsy findings in two patients with TAFRO syndrome: Case presentations and review of the literature. BMC Nephrol. 2020, 21, 499. [CrossRef]

13. Mizuno, H.; Sekine, A.; Oguro, M.; Oshima, Y.; Kawada, M.; Sumida, K.; Yamanouchi, M.; Hayami, N.; Suwabe, T.; Hiramatsu, R.; et al. Renal histology in a patient with TAFRO syndrome: A case report. Hum. Pathol. 2018, 82, 258-263. [CrossRef] [PubMed]

14. Imafuku, A.; Suwabe, T.; Hasegawa, E.; Mise, K.; Sumida, K.; Hiramatsu, R.; Yamanouchi, M.; Hayami, N.; Hoshino, J.; Sawa, N.; et al. Castleman's disease accompanied by hypolipidemic cerebral hemorrhage and nephrosclerosis. Intern. Med. 2013, 52, 1611-1616. [CrossRef] [PubMed]

15. Tanaka, J.; Fujita, A.; Hosoda, K.; Kohmura, E. Cerebral angiitis associated with subarachnoid hemorrhage in Castleman's disease, report of two cases. BMC Neurol. 2016, 16, 60. [CrossRef] [PubMed]

16. Kubokawa, I.; Yachie, A.; Hayakawa, A.; Hirase, S.; Yamamoto, N.; Mori, T.; Yanai, T.; Takeshima, Y.; Kyo, E.; Kageyama, G.; et al. The first report of adolescent TAFRO syndrome: A unique clinicopathologic variant of multicentric Castleman's disease. BMC Pediatr. 2014, 14, 139. [CrossRef]

17. Takayama, Y.; Kubota, T.; Ogino, Y.; Ohnishi, H.; Togitani, K.; Yokoyama, A. TAFRO syndrome with disseminated intravascular coagulation successfully treated with tocilizumab and recombinant thrombomodulin. Intern. Med. 2018, 57, 1291-1296. [CrossRef]

18. Nara, M.; Komatsuda, A.; Itoh, F.; Kaga, H.; Saitoh, M.; Togashi, M.; Kameoka, Y.; Wakui, H.; Takahashi, N. Two cases of thrombocytopenia, anasarca, fever, reticulin fibrosis/renal failure, and organomegaly (TAFRO) syndrome with high serum procalcitonin levels, including the first case complicated with adrenal hemorrhaging. Intern. Med. 2017, 56, 1247-1252. [CrossRef] [PubMed]

19. Iwaki, N.; Fajgenbaum, D.C.; Nabel, C.S.; Gion, Y.; Kondo, E.; Kawano, M.; Masunari, T.; Yoshida, I.; Moro, H.; Nikkuni, K.; et al. Clinicopathologic analysis of TAFRO syndrome demonstrates a distinct subtype of HHV-8-negative multicentric Castleman disease. Am. J. Hematol. 2016, 91, 220-226. [CrossRef] [PubMed]

20. Fujimoto, S.; Kawabata, H.; Sakai, T.; Yanagisawa, H.; Nishikori, M.; Nara, K.; Ohara, S.; Tsukamoto, N.; Kurose, N.; Yamada, S.; et al. Optimal treatments for TAFRO syndrome, a retrospective surveillance study in Japan. Int. J. Hematol. 2021, 113, 73-80. [CrossRef] 
21. Coutier, F.; Meaux Ruault, N.; Crepin, T.; Bouiller, K.; Gil, H.; Humbert, S.; Bedgedjian, I.; Magy-Bertrand, N. A comparison of TAFRO syndrome between Japanese and non-Japanese cases: A case report and literature review. Ann. Hematol. 2018, 97, 401-407. [CrossRef]

22. Fajgenbaum, D.C.; Langan, R.A.; Japp, A.S.; Partridge, H.L.; Pierson, S.K.; Singh, A.; Arenas, D.J.; Ruth, J.R.; Nabel, C.S.; Stone, K.; et al. Identifying and targeting pathogenic PI3K/AKT/mTOR signaling in IL-6-blockade-refractory idiopathic multicentric Castleman disease. J. Clin. Investig. 2019, 129, 4451-4463. [CrossRef] [PubMed]

23. Arenas, D.J.; Floess, K.; Kobrin, D.; Pai, R.L.; Srkalovic, M.B.; Tamakloe, M.A.; Rasheed, R.; Ziglar, J.; Khor, J.; Parente, S.A.T.; et al. Increased mTOR activation in idiopathic multicentric Castleman disease. Blood 2020, 135, 1673-1684. [CrossRef] [PubMed]

24. Pai, R.L.; Japp, A.S.; Gonzalez, M.; Rasheed, R.F.; Okumura, M.; Arenas, D.; Pierson, S.K.; Powers, V.; Layman, A.A.K.; Kao, C.; et al. Type I IFN response associated with mTOR activation in the TAFRO subtype of idiopathic multicentric Castleman disease. JCI Insight 2020, 5, e135031. [CrossRef] [PubMed]

25. Ivashkiv, L.B.; Donlin, L.T. Regulation of type I interferon responses. Nat. Rev. Immunol. 2014, 14, 36-49. [CrossRef] 